\title{
EKSISTENSI TRADISI LISAN CAKAP LUMAT DALAM UPACARA ADAT PERKAWINAN KARO
}

\author{
Sylvie Meiliana \\ Universitas Nasional Jakarta \\ email: sylviemeiliana@gmail.com
}

\begin{abstract}
Abstrak
Masyarakat Karo selalu menggunakan tradisi lisan dalam berbagai jenis kegiatan upacara adat. Salah satu bentuk tradisi lisan masyarakat Karo adalah Cakap Lumat yang digunakan dalam upacara adat perkawinan. Penelitian ini bertujuan mendeskripsikan pelaku, bentuk kebahasaan, dan fungsi tuturan dalam tradisi lisan Cakap Lumat dalam upacara adat masyarakat Karo. Sumber data penelitian adalah tuturan lisan Cakap Lumat dalam upacara adat perkawinan karo di Dusun Tongkoh, Desa Dolat Rakyat, Kecamatan Dolat Rakyat dengan informan kunci Nande Beru Tarigan. Pengumpulan data dengan teknik perekaman dan transkripsi. Anasisis data menggunakan teknik analisis isi dengan model alir. Hasil penelitian sebagai berikut. Pertama, tuturan Cakap Lumat dilakukan oleh seseorang sesuai posisinya dalam status sosial, yakni kalimbubu, senina, dan anak beru. Kedua, bentuk kebahasan Cakap Lumat, yaitu bahasa kiasan dan perumpamaan. Ketiga, Cakap Lumat berfungsi untuk ucapan salam, ucapan doa, konfirmasi, pujian, dan nasehat.
\end{abstract}

Kata kunci: tradisi lisan, bentuk dan fungsi Cakap Lumat, masyarakat Karo

\section{EXISTENCE OF ORAL TRADITIOAN CAKAP LUMAT IN WEDDING CEREMONY IN KARO SOCIETY}

\begin{abstract}
The Karo people always use oral traditions in various types of traditional ceremonial activities. One form of the oral traditions of the Karo people is Cakap Lumat which is used in traditional marriage ceremonies. This study is aimed at describing the speech performers, forms of language, and the function of the oral tradition of Cakap Lumat in the traditional ceremony of the Karo community. The data source of the study is oral speech of Cakap Lumat in a traditional karo marriage ceremony in Tongkoh village, Dolat Rakyat Village, Dolat Rakyat District with key informant Nande Beru Tarigan. Data collection is by recording and transcription techniques. Data analysis uses content analysis techniques with flow models. The results of the study are as follows. First, Cakap Lumat is done by someone according to his/her position in social status, namely kalimbubu, senina, and anak beru. Second, the forms of the language of Cakap Lumat are figurative language and parables. Third, the function of Cakap Lumat is for giving greetings, blessing, confirmation, praise, and advice.
\end{abstract}

Keywords: oral tradition, form and function, Cakap Lumat, Karo people 


\section{PENDAHULUAN}

Setiap suku memiliki ragam kesenian seperti sastra lisan yang dapat ditemukan dalam setiap upacara yang dilakukan. Sastra lisan adalah kesusastraan yang mencakup ekspresi kesusastraan warga suatu kebudayaan yang disebarkan dan diturun-temurunkan (dari mulut ke mulut) (Girsang, 2019). Sastra lisan pada umumnya dihubungkan dengan aktivitas sehari-hari yang dilakukan masyarakat setempat. Salah satunya aktivitas tersebut adalah pelaksanaan adat perkawinan.

Penelitian Sulissusiawan (2016) menjelaskan peran Muhakam dalam adat perkawinan masyarakat Melayu Sambas. Peran Muhakam merupakan representasi adab dan etika dalam adat perkawinan Melayu Sambas. Ucapan Muhakam menggambarkan hati yang ikhlas, penuh kasih sayang, dan belas kasihan. Muhakam memperlihatkan strategi ikhlas, merendah diri, dan meminta maaf sebagai representasi adab dan etika Melayu. Adab dan etika Muhakam dalam acara majelis adat perkawinan Melayu ditunjukkan dengan sikap dan perilaku yang dapat menumbuhkan simpati dan respon yang baik dari masyarakat. Kebijaksanaan dan kesantunan dalam berperilaku ditunjukkan oleh Muhakam dengan senyum, bertegur sapa, berjabat tangan, dan adab berpakaian. Peran penting tersebut menjadikan seorang Muhakam dianggap sebagai sosok yang dapat menjaga marwah keluarga dan masyarakat.

Pada masyarakat Kabupaten Pamekasan Madura dikenal adanya sastra lisan Mamaca. Sastra lisan mamaca dikembangkan oleh komunitas "Rukun Sampurna" dengan pentas secara rutin dan melayani permintaan atau undangan masyarakat untuk acara-acara tertentu. Sastra lisan mamaca berfungsi mendorong masyarakat menuju tataran yang lebih baik melalui pesan-pesan yang disampaikan. Penonton akan memperoleh inspirasi terkait dengan semangat hidup, optimisme, pencerahan, dan kebahagiaan (Kusmayati \& Sayuti, 2014).

Demikian halnya dengan masyarakat Karo di Sumatera Utara. Karo adalah salah satu suku Batak di dataran tinggi Sumatera Utara. Suku-suku lainnya adalah Angkola, Mandailing, Pakpak, Simalungun, dan Toba. Tanah Karo mencakup seluruh Kabupaten Karo, seperti Langkat, Dairi, Simalungun, Aceh Selatan, dan Deli Serdang (Singarimbun, 2015; Kipp, 2017). Ini adalah daerah yang terutama terdiri dari gunung (Sinabung dan Sibayak) dan dataran tinggi (Anderson, 2015; Singarimbun, 2017). Kabanjahe adalah salah satu kecamatan yang terletak di Kabupaten Karo, Provinsi Sumatera Utara. Kabanjahe juga merupakan Ibu Kota Tanah Karo. Nama lain Kabupaten ini adalah "Tanah Karo Simalem" (Tanah Karo yang Permai) (Lubis, 2017).

Tanah Karo dibagi menjadi daerah dataran tinggi dan dataran rendah (Singarimbun, 2017). Orang Karo menamai pemukiman dataran tinggi Karo Gugung dan pemukiman dataran rendah Karo Jahe. Wilayah dataran tinggi Tanah Karo dianggap sebagai pusat budaya dan tanah leluhur komunitas Karo. Di wilayah ini, bahasa tidak banyak tersentuh oleh pengaruh luar, sehingga ikatan kekerabatan dan kehidupan tradisional masih sangat kuat (Ginting, 2016). Daerah pemukiman 
dataran rendah di Kabupaten Langkat dan Kabupaten Deli Serdang umumnya lebih berorientasi pada produksi tanaman budidaya seperti karet dan kelapa sawit. Wilayah dataran rendah Karo menyerap pengaruh melayu pesisir dan menjadi muslim. Itulah sebabnya mereka terkadang harus mengesampingkan klan mereka dan ini membuat hubungan kekerabatan dengan saudara mereka di dataran tinggi terputus (Ginting, 2016).

Dalam komunitas Karo, ada sejumlah prinsip sebagai dasar kehidupan tradisional yang disebut palas kegeluhen ibas adat. Ini menggambarkan karakteristik kehidupan masyarakat Karo yang diterapkan dalam kehidupan seharihari yang mencakup aspek kebiasaan mereka. Orang Karo ditandai dengan nama klan yang disebut Merga Silima yang diwarisi secara patrilineal. Merga Silima terdiri dari lima nama klan (merga) dan masing-masing memiliki sekitar 5-15 sub-merga (Sembiring, 2016:1).

Komunitas Karo biasanya menerapkan sastra lisan sebagai tradisi yang digunakan pada upacara tradisional, seperti melamar seorang gadis, upacara pernikahan, upacara kelahiran anak, upacara menghormati orang tua, upacara kematian, upacara peletakan batu pertama membangun rumah, upacara memasuki sebuah rumah baru, upacara pemanggilan arwah, upacara penanaman dan panen padi, upacara pesta tahunan, upacara penolakan roh-roh jahat, upacara pemanggilan hujan, dan upacara penolakan hujan.

Ada enam bentuk sastra lisan yang terkenal di komunitas Karo (Tarigan, 2011). Pertama, Ndungdungen. Ini hampir sama dengan pantun Melayu, biasanya terdiri dari 4 baris berima abab. Dua baris pertama berisi sampiran dan dua baris terakhir adalah konten. Kedua, Bilang-bilang. Ini adalah bentuk kesedihan, biasanya dinyanyikan dengan ratapan oleh orang-orang yang telah mengalami kesedihan, seperti ibu yang telah meninggal, meratapi kekasih yang telah diambil oleh orang lain atau pergi ke luar negeri. Ketiga, Cakap Lumat. Ini adalah bahasa lunak yang penuh dengan bahasa kiasan, pepatah, perumpamaan, sajak, dan teka-teki. Keempat, Turinturin. Ini adalah cerita dalam bentuk prosa, misalnya tentang asal mula klan, asal-usul desa, kisah bintang, kisah orang-orang ajaib, cerita lucu dan lainlain. Biasanya diceritakan oleh orang tua pada malam sebelum tidur. Kelima, Tabas-Tabas. Ini adalah mantra, yang umumnya hanya dukun yang tahu. Keenam, Kuning-kuningen. Ini adalah teka-teki yang digunakan oleh anakanak, orang muda, dan orang dewasa di waktu luang mereka sebagai permainan selain mengasah otak (https://Karo.or. id/sastra-Karo-selayang-dipandang/ 2011).

Dalam komunikasi sehari-hari, penggunaan bahasa Karo tidak memerlukan kosakata tertentu, tetapi dalam upacara tradisional seperti upacara pernikahan, bahasa yang digunakan tidak sama dengan bahasa yang digunakan sehari-hari. Sebagai salah satu karya sastra, Cakap Lumat digunakan untuk komunikasi dalam upacara tradisional. Cakap Lumat adalah pidato atau dialog yang menggunakan kata-kata yang sangat sopan dengan pilihan kosa kata yang dianggap paling tepat. Cakap 
Lumat adalah dialog yang diselingi dengan kiasan, perumpamaan, dan rima untuk mempercantik dan membuatnya lebih menarik.

Sastra lisan dapat menjadi salah satu upaya pemahaman tindakan sosial dengan mempertimbangkan kehidupan masyarakat sebagai jaringan yang kompleks, saling berhubungan, tergantung dan bermakna, konstruksi realitas sosial yang dimiliki oleh setiap anggota kelompok, komunitas atau masyarakat (Lubis, 2018). Penelitian ini bertujuan mendeskripsikan bentuk kebahasaan, pelaku tuturan dan fungsi tradisi lisan Cakap Lumat dalam upacara perkawinan adat masyarakat Karo.

\section{METODE}

Pendekatan penelitian yang digunakan dalam penelitian ini adalah penelitian deskriptif kualitatif dengan metode analisis data (content analysis). Sumber data penelitian adalah tuturan lisan Cakap Lumat dalam upacara adat perkawinan Karo di Dusun Tongkoh, Desa Dolat Rakyat, Kecamatan Dolat Rakyat dengan informan kunci Nande Beru Tarigan. Pengumpulan data dengan teknik perekaman dan transkripsi. Analisis data menggunakan teknik analisis isi dengan model alir. Analisis data dilakukan untuk mendeskripsikan bentuk kebahasaan, pelaku tuturan dan juga fungsi tradisi lisan Cakap Lumat dalam upacara adat masyarakat Karo. Analisis dilanjutkan dengan penarikan simpulanberdasarkan pada permasalahan yang menjadi fokus penelitian.

\section{HASIL DAN PEMBAHASAN}

Hasil

Di dalam komunitas Karo dikenal kedudukan sebagai Anak Beru, Senina, dan Kalimbubu (Rakut Sitelu) yang selalu mempunyai peran penting di acara-acara adat seperti pesta perkawinan adat Karo (Ginting, 2018). Pada upacara adat tersebut, Cakap Lumat adalah dialog yang digunakan di antara Kalimbubu, Senina, dan Anak Beru selama prosesi adat. Dalam Cakap Lumat, pembicara harus menggunakan bahasa yang sangat sopan untuk menghindari konflik antara pembicara dalam proses komunikasi (Ginting, 2017).

Sesuai dengan fokus, hasil penelitian mencakup tiga hal, yaitu pelaku, bentuk kebahasaan, dan fungsi Cakap Lumat dalam adat pernikahan masyarakat Karo. Hasil selengkapnya disajikan pada Tabel 1.

Tabel 1 Pelaku, Bentuk Kebahasaan, dan Fungsi Tradisi Lisan Cakap Lumat

\begin{tabular}{cll}
\hline No. & Aspek & Deskripsi \\
\hline 1. & Pelaku & a. Kalimbumbu \\
& & b. Senina \\
& & c. Anak Beru \\
2. & Bentuk & a. Bahasa Kiasan \\
& Kebahasaan & b. Perumpamaan \\
3. Fungsi & a. Ucapan Salam \\
& & b. Ucapan Doa \\
& & c. Konfirmasi \\
& d. Pujian \\
& e. Nasehat \\
\hline
\end{tabular}

\section{Pembahasan}

Sebagaimana disajikan pada hasil, pembahasan penelitian juga mencakup tiga aspek, yakni pelaku tuturan, bentuk kebahasaan, dan fungsi tuturan Cakap Lumat dalam tradisi perkawinan adat 
masyarakat Karo. Ketiga hal tersebut selanjutnya diuraikan dalam sub-subab berikut.

\section{Pelaku Tuturan Tradisi Lisan Cakap Lumat}

Dalam tradisi adat perkawinan masyarakat Karo, tuturan Cakap Lumat dilakukan oleh seseorang sesuai posisinya dalam status sosial, yakni Kalimbubu, Senina, dan Anak Beru.

Pertama, posisi Kalimbumbu. Kalimbubu merupakan keluarga dalam Rakut Sitelu menempati posisi yang paling tinggi. Oleh karena itu, pihak Kalimbubu sebagai pemberi perempuan sangat dihormati dalam sistem kekerabatan masyarakat Batak Karo. Masyarakat Batak Karo meyakini bahwa Kalimbubu adalah pembawa berkat. Sikap menentang dan menyakiti hati Kalimbubu sangat dicela dan tidak diperkenankan. Dalam hal memberi nasihat, semua nasihat yang diberikan Kalimbubu dalam suatu musyawarah keluarga menjadi masukan yang harus dihormati dan dihargai (Fitriani, 2015).

Kedua, posisi Senina. Status sosial Senina merujuk pada Rakut Sitelu adalah mereka yang memiliki hubungan darah dan mempunyai marga yang sama. Senina adalah teman semarga yang lakilaki, baik yang kandung maupun yang berkerabat dekat. Senina adalah hubungan kekerabatan berdasarkan marga yang sama. Senina bertugas memimpin pembicaraan dalam musyawarah dan berperan sebagai sekat dalam pembicaraan adat agar tidak terjadi friksi-friksi ketika akan memusyawarahkan pekerjaan yang akan didelegasikan kepada Anak Beru (Fitriani, 2015).
Ketiga, posisi Anak Beru. Anak Beru adalah pihak pengambil perempuan atau penerima perempuan untuk diperistri. Anak Beru disebut pula hakim moral, karena bila terjadi perselisihan dalam keluarga Kalimbubu-nya, tugasnyalah mendamaikan perselisihan tersebut. Ginting, Hidayah, \& Lasan (2019) menjelaskan bahawa Anak Beru mempunyai peran yang aktif dalam berbicara (Anak Beru si ngerana) pada saat pesta adat berlangsung. Tidak semua yang mempunyai kedudukan Anak Beru mampu menjadi Anak Beru Singerana (Anak Beru yang berbicara), karena Anak Beru Singerana inilah yang dituntut dapat berkomunikasi dengan bahasa santun (mehamat) serta pintar merangkai kata-kata saat berbicara dengan Kalimbubu (orang yang dihormati).

\section{Bentuk Kebahasaan Cakap Lumat}

Dalam tradisi adat perkawinan masyarakat Karo, bentuk kebahasaan tuturan Cakap Lumat, yaitu bahasa kiasan dan peribahasa perumpamaan.

Pertama, bahasa kiasan. Bahasa kiasan adalah ungkapan yang digunakan untuk memberi warna atau kekuatan pada ucapan atau tulisan (Wainwright, 2004:185). Menurut Perriene (1983:576) bahasa kiasan adalah bahasa yang tidak menggunakan bahasa pada umumnya atau merupakan cara lain untuk mengatakan suatu yang lain dari cara yang biasanya atau dalam hal ini bahasa yang digunakan. Bahasa kiasan adalah sebuah kebiasaan berspekulasi dalam memahami sebuah bahasa sebagai pengertian standar kalimat, atau hasil. Selanjutnya diungkapkan Krause (2008:13) bahasa kiasan mengacu pada 
sudut pandang "secara tidak langsung" atau "logis" yang mempertahankan bahwa awal analisis untuk arti secara harafiah dan jika tafsiran tidak masuk akal, maka proses kalimat kembali ke bahasa kiasan yang sesuai.

Penggunaan bahasa kiasan dalam tuturan lisan Cakap Lumat oleh Kalimbubu tampak pada tuturan sebagai berikut.

Bujur kataken kami man kam kerina keluarga si enggo er meriah ukur ndahi kerja peradaten kempu, bebere, permen ntah pe impal ndu enda. Ija er mengkah kel ukur kami, ibas kerehenndu kerina, Dibatalah simasu-masu kerina pendahin ndu, apai kurang akap ndu pendudurken isap ras kampil man bandu ula tama sangkut ukur ndu, sebab bas kami Kalimbubu ndu pe melala denga kekurangen.

(Kami mengucapkan terima kasih kepada semua keluarga yang sudah dengan sukacita/gembira menghadiri pernikahan adat cucu, keponakan, menantu ataupun impal kalian. Kami sangat bahagia atas kehadiran kalian semua. Tuhanlah yang memberkati semua pekerjaan kalian, sekiranya menurut kalian ada kekurangan kami dalam menanggapi/menyambut kalian, jangan sakit hati sebab kami sebagai Kalimbubu kalian masih banyak kekurangan.)

Dalam sambutan di atas, Kalimbubu menggunakan tuturan Cakap Lumat dengan memperhatikan aspek-aspek sebagai berikut. Pertama, penggunaan diksi halus kam dan $n d u$ untuk orang kedua. Kedua, penggunaan bahasa kiasan si enggo er meriah ukur ndahi kerja peradaten yang berarti dengan senang hati menghadiri acara adat tersebut. Frasa meriah ukur merupakan tuturan halus yang digunakan oleh Kalimbubu. Ketiga, tuturan apai kurang akap ndu pendudurken isap ras kampil man bandu ula tama sangkut ukur ndu berarti Kalimbubu dengan nada yang sangat sopan/halus meminta maaf jika ada kekurangan dalam penyambutan mereka. Frasa pendudurken isap ras kampil adalah bahasa kiasan yang berarti menyambut, karena dalam adat Karo biasanya tamu disambut dengan menyampaikan rokok dan sirih. Keempat, tuturan ula tama sangkut ukur ndu adalah bahasa kiasan yang disampaikan oleh Kalimbubu untuk meminta maaf atas kekurangan mereka (Girsang, 2019).

Penggunaan bahasa kiasan tuturan lisan Cakap Lumat oleh Senina sebagai berikut.

Mejuah-juah Senina, mari Senina arenda inganta, ras ise ndaikam reh?

(Salam Senina, mari kesini Senina, ini tempat kita. Kalian datang dengan siapa?)

Dalam tuturan di atas, Senina menyambut para tamu (sesama Senina) dengan memberi salam Menjuah-juah. Ginting, dkk. (2019) mengungkapkan mejuah juah adalah suatu salam suku Karo, namun tidak hanya salam biasa saja, karena di dalamnya terkandung sebuah makna yang menjadikan orang Karo berada di dalam kejuah-juahen (damai sejahtera, bahagia dan sehat). Dalam menyampaikan salam, Senina menggunakan bahasa kiasan mejuahjuah yang artinya sehat lahir bathin. 
Mereka melakukan konfirmasi kepada sesama Senina mengenai tempat duduk mereka sesuai adat dan tradisi mari Senina arenda inganta. Kedua adalah konfirmasi berapa orang yang hadir dengan menanyakan ras ise ndaikam reh? Dalam situasi ini Senina menggunakan diksi yang halus kam untuk orang kedua.

Penggunaan bahasa kiasan tuturan lisan Cakap Lumat oleh Anak Beru sebagai berikut.

Kam kerina Anak Beru sembiring mari kam ku jenda, enda amak ndu gelah benaken rungguta. Adi enggo kam pulung enda tanda-tandana. Dung kari lebe kerja maka kam baci lawes.

(Untuk semua Anak Beru Sembiring, mari ke sini, ini tikar tempat duduk kalian agar kita memulai pertemuan. Itu artinya kalian semua sudah berkumpul. Setelah selesai kerja adat, baru kalian bisa pulang.)

Ketika mereka memberikan ucapan salam, Anak Beru terlihat sangat sopan dengan menggunakan Cakap Lumat. Dalam komunikasi sehari-hari, mereka mengatakan kena kerina (kalian semua) untuk orang kedua jamak, yaitu para Anak Beru yang hadir. Namun dalam kesempatan ini, yaitu acara adat, mereka menggunakan menggunakan frasa $\mathrm{kam}$ kerina (kalian semua). Anak Beru menggunakan bahasa kiasan mari kam ku jenda, enda amakndu gelah benaken rungguta untuk memberitahukan posisi tempat mereka harus duduk agar mereka dapat segera melakukan pembicaraan terkait dengan persiapan pesta perkawinan adat. Bahasa kiasan Dung kari lebe kerja maka kam baci lawes digunakan Anak Beru kepada sesama Anak Beru agar tidak meninggalkan pesta adat sebelum acara selesai (Ginting \& Efendi, 2017).

Kedua, bentuk perumpaaan. Perumpamaan adalah suatu peribahasa yang digunakan seseorang dengan cara membandingkan atau mengibaratkan suatu keadaan atau tingkah laku seseorang dengan keadaan alam, benda, atau makhluk alam semesta. Perumpamaan adalah peribahasa yang biasanya didahului oleh perkataan seperti seolaholah, ibarat, bak, seperti, laksana, macam, bagai, dan umpama, untuk menyamakan suatu hal dengan hal lain. Peribahasa merupakan salah satu karya sastra dalam bahasa Indonesia. Peribahasa memiliki beberapa macam bentuk, diantaranya peribahasa pepatah, perumpamaan, dan pemeo. Peribahasa adalah kalimat yang menyatakan suatu situasi, kondisi yang mengungkapkan perbuatan, tingkah laku mengenai diri seseorang. Peribahasa perumpamaan adalah perbandingan antara perilaku manusia dengan sesuatu yang ada di alam sekitarnya. Berdasarkan pembentukan katanya, perumpamaan dapat dipisah menjadi per-umpama-an yang memiliki kata dasar 'umpama' yang berarti 'seperti'. Perumpamaan dicirikan dengan kalimat yang diawali dengan kata seperti, bak, atau bagai. Peribahasa adalah kalimat atau kelompok perkataan yang biasanya mengiaskan sesuatu maksud tertentu (Hartati, 2015). Peribahasa merupakan tuturan tradisional yang mengandung makna kias, tidak mengandung makna simile (Pulungan, 2013: 3).

Penggunaan bentuk perumpaan dalam tuturan lisan Cakap Lumat oleh Kalimbumbu sebagai berikut. 
Man kam bebere kami si enggo njabuken bana, enda kami mama ras mami ndu tedis $i$ jenda nehken luah ras pasu-pasu man bandu duana. Sangap kam njabuken bana duana simpar rejeki si rehman kam, bagi perbincar matawari nerangi doni.

(Kepada keponakan kami yang sudah menikah, kami mama (paman) dan mami (istri paman) kalian berdiri disini untuk menyampaikan kado dan doa kepada kalian berdua. Selamat untuk kalian berdua, semoga diberikan banyak rejeki.)

Dalam tuturan di atas, Kalimbubu menggunakan Cakap Lumat, seperti: (a) penggunaan kata halus kam dan $n d u$ untuk orang kedua, (b) menyampaikan doa kepada kedua mempelai agar diberkati Tuhan dan diberikan rejeki yang melimpah. Dalam menyampaikan doanya, Kalimbubu menggunakan ungkapan peribahasa perumpamaan bagi perbincar matawari nerangi doni (seperti matahari menerangi bumi) untuk mengungkapkan banyak rejeki (Lubis, 2017).

Berikut adalah Cakap Lumat yang disampaikan Kalimbubu kepada Anak Beru mereka. Kalimbubu berterima kasih, memuji pekerjaan mereka, dan berdoa agar mereka diberkati Tuhan.

Mbue kataken kami bujur man kam Anak Beru kami, kam sekin telap kami bas keluarga ginting mergana. Dibata simasumasu kerina pendahin ndu. La kami ngasup ngulihken kini ulin ndu dibatalah pagi simbalas sa kerina.

(Kami ucapkan banyak terima kasih kepada Anak Beru kami. Kalian sungguh-sungguh hebat/luar biasa dalam keluarga bermarga Ginting.
Semoga Tuhan memberkati semua pekerjaan kalian. Kami tidak dapat membalas kebaikan kalian, Tuhanlah yang akan membalas semua.)

Dalam tuturan di atas, Kalimbubu menggunakan tuturan halus seperti kam dan $n d u$ untuk orang kedua. Dalam mengungkapkan rasa terima kasih kepada Anak Beru, mereka menggunakan peribahasa perumpamaan sekin telap (pisau yang tajam) untuk mengungkapkan kehebatan Anak Beru sebagai penolong Kalimbubu dalam pesta adat tersebut. Tuturan ngulihken kini ulin ndu juga merupakan bentuk peribahasa perumpamaan yang artinya 'untuk membalas semua kebaikanmu'.

Penggunaan bentuk perumpaan dalam tuturan lisan Cakap Lumat oleh Senina seperti tampak pada kutipan berikut.

Man kam dua na pengantin, Sangap ertuah bayak kam duana, jumpa bulan ras matawari ras merih manuk niasuh mbuah page sini isuan, ras kai siisuraken ndu iamin ken Dibata kerina.

(Kepada kedua mempelai, semoga kalian berdua memperoleh rejeki yang berlimpah, sukses dalam pekerjaan, dan semua doa kalian dikabulkan Tuhan.)

Dalam tuturan di atas, Senina mendoakan kedua mempelai. Mereka menggunakan Cakap Lumat, seperti: a) frasa kam duanya, penggunaan diksi kam merupakan kata halus untuk orang kedua; b) frasa jumpa bulan ras matawari merupakan perumpamaan yang digunakan Senina untuk menyampaikan 
doa mereka agar pasangan mempelai diberiketurunanlaki-laki dan perempuan. Perumpamaan ertuah bayak juga digunakan Senina untuk mendoakan kedua mempelai agar mendapatkan rezeki yang melimpah. Dalam tuturan merih manuk niasuh mbuah page sini isuan, Senina menggunakan perumpamaan untuk mendoakan kedua mempelai agar sukses dalam pekerjaan/karier.

Tuturan lisan Cakap Lumat oleh Anak Beru menggunakan perumpamaan rubatlah kam muat si mehulina yang artinya kalian dapat ribut selama demi untuk kebaikan. Perumpamaan ini memiliki arti tersirat bahwa bila terpaksa ribut tidak masalah selama demi untuk kebaikan.

Dalam upacara pernikahan tradisional Karo, Cakap Lumat terlihat dari penggunaan tuturan $\mathrm{kam}$ dan $n d u$ untuk orang kedua, demikian juga penggunaan frasa ngukati man ciger yang berarti makan siang. Kata ngukati digunakan untuk memperhalus frasa man ciger yang pada umumnya digunakan dalam bahasa sehari-hari. Anak Beru juga menggunakan perumpamaan kata nangkihna matawari (naiknya matahari) yang bermakna hari beranjak siang. Cakap Lumat ini digunakan oleh Anak Beru kepada Kalimbubu mereka untuk memperoleh konfirmasi mengenai waktunya makan siang.

Man kam Kalimbubukami, ibasnangkihna matawari enda ku cigerna nungkun ate kami melabo akap ndu salah adi pas kari jam 12 kari i je kita ngukati man ciger.

(Kepada Kalimbubu kami, karena sudah siang, kami ingin bertanya apakah sudah waktunya bagi kita untuk makan siang)

\section{Fungsi Tuturan Lisan Cakap Lumat}

Dalam tradisi adat perkawinan masyarakat Karo, terdapat lima fungsi tuturan Cakap Lumat, yaitu ucapan salam, ucapan doa, konfirmasi, pujian, dan nasehat. Kelima fungsi tersebut secara terperinci diuraikan sebagai berikut.

Pertama, Ucapan Salam. Pada saat pesta perkawinan adat, Kalimbubu menyapa para tamu yang telah hadir dengan ucapan salam. Berikut adalah tuturan yang disampaikan Kalimbubu untuk menyampaikan salam.

Bujur kataken kami man kam kerina keluarga si enggo er meriah ukur ndahi kerja peradaten kempu,bebere, permen ntah pe impal ndu enda. Ija er mengkah kel ukur kami, ibas kerehenndu kerina, Dibatalah simasu-masu kerina pendahin ndu, apai kurang akap ndu pendudurken isap ras kampil man bandu ula tama sangkut ukur $n d u$, sebab bas kami Kalimbubu ndu pe melala denga kekurangen.

(Kami mengucapkan terima kasih kepada semua keluarga yang sudah dengan sukacita/gembira menghadiri pernikahan adat cucu, keponakan, menantu ataupun impal kalian. Kami sangat bahagia atas kehadiran kalian semua. Tuhanlah yang memberkati semua pekerjaan kalian, sekiranya menurut kalian ada kekurangan kami dalam menanggapi/menyambut kalian, jangan sakit hati sebab kami sebagai Kalimbubu kalian masih banyak kekurangan.)

Kutipan berikut merupakan ucapan salam yang disampaikan Senina ketika mereka menyambut tamu yang hadir dalam pesta perkawinan adat. 
Mejuah-juah Senina, mari Senina arenda inganta, ras ise ndaikam reh? (Salam Senina, mari kesini Senina, ini tempat kita. Kalian datang dengan siapa?)

Anak Beru menyampaikan ucapan salam, yaitu selamat datang kepada sesama Anak Beru menjelang rapat keluarga (runggu) persiapan pelaksanaan upacara pernikahan adat.

Kam kerina Anak Beru sembiring mari kam ku jenda, enda amak ndu gelah benaken rungguta. Adi enggo kam pulung enda tanda-tandana. Dung kari lebe kerja maka kam baci lawes.

(Untuk semua Anak Beru Sembiring, mari ke sini, ini tikar tempat duduk kalian agar kita memulai pertemuan. Itu artinya kalian semua sudah berkumpul. Setelah selesai kerja adat, baru kalian bisa pulang.)

Kedua, ucapan doa. Pada acara perkawinan adat Karo, Kalimbubu menyampaikan doa kepada puang Kalimbubu mereka agar mereka senantiasa sehat-sehat, sejahtera, dan diberikan kesuksesan seperti terungkap dalam tuturan berikut.

Man kam Puang Kalimbubu kami, bujur melala $i$ kataken kami man bandu enggo $i$ sempat kendu reh lako ndungi adat bebere ndu. Megogo kel ate kami i bas wari sendah, la kepe er keri-kerin kekelengen ndu man kami kerina, amin gia nande beru sembiring $i$ tengah-tengah jabu lanai $i$ rumah. La kurang kite-kite ta er kade kade bujur melala $i$ kataken kami, sehat-sehat kita kerina. Dibata simasu masu kerina kini ulinndu.
Mejuah-juah sangap encari kita kerina.

(Kepada Puang Kalimbubu kami, kami ucapkan banyak berterima kasih karena telah menyempatkan diri untuk menghadiri dan menyelesaikan adat keponakan kalian. Hari ini kami sangat bersedih dan terharu karena walaupun ibu kami beru Sembiring sudah meninggal dunia, tetapi kalian masih tetap menyayangi kami. Kita tetap bersaudara, kami ucapkan banyak terima kasih, semoga kita semua sehatsehat. Tuhan memberkati kita semua atas kebaikan kalian. Semoga kita semua bahagia, sehat, dan sukses dalam pekerjaan).

Dalam tuturan berikut Senina mendoakan kedua mempelai agar diberkati Tuhan, dapat menjalankan kehidupan keluarga dengan damai sejahtera dengan rejeki yang melimpah.

Man kam Senina kami si njabuken bana $i$ bas wari enda, sue $i$ bas percakapenta ibas piga-piga wari si lewat meriah kel ukur kami mbegi berita si meriah enda. I bas kam manteki jabu simbaru njujuri Dibata sangap ertuah bayak kam duana. Apai pagi kam lit ibas perbeben geluh turiken ndu lah man kami Seninandu, asa ngasup kami i sampati kami kam, ula latih ibahan ndu ukur orang tua, maka cawir metua ia man penggurun ta kerina.

(Kepada Senina kami yang menikah pada hari ini, setelah kesepakatan beberapa hari yang lalu, kami sangat berbahagia mendengar berita bahagia ini. Dalam menjalani keluarga yang baru, semoga kalian berdua diberkati 
Tuhan, hidup damai dan bahagia serta diberikan rejeki yang melimpah. Apabila nantinya kalian menghadapi masalah, beritahu kami Senina kalian agar kami bisa membantu kalian. Jangan kalian membuat orang tua kalian letih/susah agar mereka bisa menjadi tempat untuk dimintai nasehat oleh kami semua)

Kutipan berikut adalah tuturan yang disampaikan Anak Beru kepada kedua mempelai. Dalam tuturan tersebut, mereka mendoakan agar pasangan pengantin diberkati oleh Tuhan dan diberi kesehatan, kekayaan, umur panjang, dan sukses dalam pekerjaan/ karier.

Man kam impal kami Sembiring mergana, ibas manteki jabu ndu si mbaru harapen kami ula kam sirubat-rubat, rubatlah kam muat si mehulina. Apai pagi la kap ndu payo perbahanen impal ta inget ndu lah $k u$ si mehulina. Ula ban seh tan ku impal ta ena, apai si la i angkana ajari ndu lah ia gelah ratur kerina .i bas kami nari sibare ngenca apai kam si nambahisa. Bujur

(Untuk impal kami Sembiring, sekarang kamu sudah menikah dan punya keluarga. Kami berharap kalian berdua dapat menjalankan kehidupan keluarga dengan damai tanpa ribut-ribut. Jika terjadi pun, itu hanya untuk kebaikan. Jika impal kami (istri kamu) melakukan kesalahan, ingatkan dia. Jangan pernah memukul. Kamu harus bisa membimbingnya untuk menjadi lebih baik agar semuanya berjalan dengan baik. Itu dari kami, jika ada yang ingin menambahkan, silakan saja. Terima kasih).
Dalam cakap lumat di atas, anak beru memberikan nasehat kepada kedua mempelai agar menciptakan kehidupan keluarga yang damai. Anak beru menggunakan bahasa halus seperti a) diksi kam dan $n d u$ (bukan engkau) untuk orang kedua seperti tercermin dalam ungkapan man kam impal kami sembiring, dan bahasa kiasan ulah kam sirubat-rubat untuk menasehati mereka agar menciptakan kehidupan keluarga yang damai sejahtera. Demikian juga jabundu bukan jabum seperti digunakan dalam tuturan sehari-hari dan la kap ndu payo ... inget ndu lah.

Ketiga, pujian. Berikut pujian yang disampaikan Kalimbubu kepada Anak Beru mereka. Kalimbubu berterima kasih, memuji pekerjaan mereka, dan berdoa agar mereka diberkati Tuhan.

Mbue kataken kami bujur man kam Anak Beru kami, kam sekin telap kami bas keluarga ginting mergana. Dibata simasumasu kerina pendahin ndu. La kami ngasup ngulihken kini ulin ndu dibatalah pagi simbalas sa kerina.

(Kami ucapkan banyak terima kasih kepada Anak Beru kami. Kalian sungguh-sungguh hebat/luar biasa dalam keluarga bermarga Ginting. Semoga Tuhan memberkati semua pekerjaan kalian. Kami tidak dapat membalas kebaikan kalian, Tuhanlah yang akan membalas semua.)

Dalam tuturan berikut Senina menyampaikan pujian kepada kedua mempelai yang telah berhasil dalam melaksanakan pesta perkawinan adat dan mereka menyampaikan kebahagiaan mereka. 
Man kam Senina kami si njabuken bana $i$ bas wari enda, sue i bas percakapenta ibas piga-piga wari si lewat meriah kel ukur kami mbegi berita si meriah enda.

(Kepada Senina kami yang menikah pada hari ini, setelah kesepakatan beberapa hari yang lalu, kami sangat berbahagia mendengar berita bahagia ini)

Dalam tuturan berikut, Anak Beru menyampaikan pujian kepada Kalimbubu karena keberhasilan pesta perkawinan adat yang sudah terselenggara.

Man kam Kalimbubu kami, sendah enggo erdalan peradaten impal kami alu mehuli. Sangap kam mama tua $i$ bas pejabuken impal kami enda, se sura sura ndu bagi si niarapken ndu. Pulung metunggung kita kerina er meriah ukur.

(Untuk Kalimbubu kami, hari ini kerja adat (upacara pernikahan tradisional) impal kami telah berlangsung dengan sukses. Beruntung anda Mama tua (paman tertua) dalam menikahkan impal kami ini, tercapai keinginan anda sesuai dengan harapan anda. Kita semua berkumpul dengan baik dan gembira.)

Keempat, konfirmasi. Pada kesempatan berbicara, Kalimbubu memberikan konfirmasi bahwa mereka sangat bersedih dan terharu karena puang Kalimbubu mereka masih terus menyayangi mereka dan berkenan hadir dalam pesta adat tersebut walaupun ibu di rumah tersebut telah meninggal dunia.

Man kam Puang Kalimbubu kami, bujur melala $i$ kataken kami man bandu enggo $i$ sempat kendu reh lako ndungi adat bebere ndu. Megogo kel ate kami i bas wari sendah, la kepe er keri-kerin kekelengen ndu man kami kerina, amin gia nande beru sembiring i tengah-tengah jabu lanai i rumah.

(Kepada Puang Kalimbubu kami, kami ucapkan banyak berterima kasih karena telah menyempatkan diri untuk menghadiri dan menyelesaikan adat keponakan kalian. Hari ini kami sangat bersedih dan terharu karena walaupun ibu kami beru Sembiring sudah meninggal dunia, tetapi kalian masih tetap menyayangi kami).

Dalam tuturan berikut, Senina menyampaikan konfirmasi jika pesta tersebut tidak meninggalkan hutang dengan menggunakan kata kiasan labo pagi $i$ keris kerna ujung e.

Ugakin akap kena bicara kerja sintua siban? Merandal, saja ngenca me labo pagi $i$ keris kerna ujung e?

(Bagaimana menurut kalian jika pesta anak tertua kita lakukan?, Cocok, hanya saja tidak ada hutang di masa depan, bukan?)

Cakap Lumat juga disampaikan Anak Beru kepada Kalimbubu untuk mendapatkan konfirmasi dan persetujuan bahwa Kalimbubu merasa bahagia dan senang anak gadis mereka (beru Ginting) menikah dengan pemuda bermarga Sembiring. Kata erdemu yang bermakna menikah digunakan dalam perkacapan ini, sementara menikah dalam bahasa sehari-hari digunakan kata empau untuk laki-laki dan sereh untuk pihak perempuan. Anak beru menggunakan bahasa kiasan keriahen ukur Kalimbubunta untuk 
mengungkapkan bahwa Kalimbubu dapat menerima dan memberikan restu atas pernikahan laki-laki marga Sembiring dan perempuan beru Ginting (Lubis, 2017).

Ate kami min nungkuni keriahen ukur Kalimbubunta Ginting mergana, ma senang nge meriah ukur Kalimbubu kami adi erdemu Kalimbubu sembiring ras beru ginting?

(Kami ingin menanyakan apakah Kalimbubu kami yang bermarga Ginting merasa senang dan bahagia jika Kalimbubu kami yang bermarga Sembiring menikah dengan anak gadis beru Ginting?)

Kelima, nasehat. Saat memberikan kado kepada kedua mempelai, Kalimbubu memberikan nasehat sebagai berikut.

Ula kam sirubat-rubat gelah er sada tendi kurumah.

(Jangan kalian ribut-ribut agar keluarga kalian hidup bahagia dan saling pengertian.)

Tidak hanya mendoakan kedua mempelai, senina juga menyampaikan nasehat agar mereka aktif di dalam acara-acara adat seperti disampaikan dalam tuturan berikut.

Adi enggo kam pejabuken bana duana, apai pagi ertenah kade-kadenta kerna simeriah ukur entah pe si er ceda ate, mejingkat kam reh gelah metunggung kita kerina pulung i je.

(Jika kalian berdua sudah menikah/ berumah tangga, ketika saudara- saudara kita mengundang/meminta hadir baik dalam suasana bahagia maupun dalam suasana duka, kalian harus rajin menghadirinya agar kita semua berkumpul dalam suasana baik dan sempurna sesuai adat.)

Dalam tuturan di atas, Senina menasehati kedua mempelai dengan menggunakan Cakap Lumat sebagai berikut. Pertama, diksi kam (kata halus) dalam tuturan adi enggo kam pejabuken bana duana dan mejingkat kam. Kedua, tuturan apai pagi ertenah kade-kadenta kerna simeriah mengukur apakah pe si er ceda ate untuk mengungkapkan dua keadaan senang dan duka, senina menggunakan bahasa kiasan. Senina menggunakan kata halus simeriah untuk suasana bahagia/gembira seperti pesta perkawinan dan si er ceda ate (hati yang luka) untuk suasana duka seperti upacara kematian (Lubis, 2017).

Anak Beru memberikan selembar kain sebagai kado (luah) mereka kepada pasangan pengantin. Pada saat yang sama mereka menasehati mereka untuk hidup harmonis, saling pengertian sampai usia tua.

Man kam impal kami Beru Ginting, ibas wari sisendah enggo kam njabuken bana, tutus lah kam duana ibas manteki jabu simbaru gelah ersada arih ndu duana sepengodak. Enda lit ndai luah si i baba kami kain panjang murah, gelah perjabun ndu pepagi panjang ras murah rejeki kam duana i bas manteki jabu si mbaru.

(Kepada impal kami Beru Ginting, hari ini kamu sudah menikah. Seriuslah kalian berdua dalam membangun rumah tangga yang baru (keluarga 
baru) agar kalian berdua saling pengertian; seia sekata di dalam membina rumah tangga. Ini kami bawa kain panjang murah sebagai kado kami, semoga pernikahan kalian abadi dan rumah tangga kalian yang baru mendapat banyak lebih rejeki.)

Berikut nasehat yang kembali disampaikan Anak Beru kepada kedua mempelai untuk kehidupan rumah tangga mereka selanjutnya.

adi enggo kam njabuken bana, sekula serasi, bagi rananta min lagunta, ras pemakenta min pergeluhta, bagepe pendahinta, maka dat buahna situhu-tuhu.

(Jika kalian sudah berumah tangga, kalian harus saling pengertian seperti yang telah disampaikan dan perbaikilah kehidupan kalian dan juga pekerjaan/ karier sehingga membuahkan hasil yang sunguh-sungguh.)

Dalam cakap lumat di atas, anak beru menyampaikan nasehat seperti: adi enggo kam njabuken bana. Dalam tuturan ini digunakan diksi kam sebagai bahasa halus untuk orang kedua jamak. Tuturan sekula serasi, bagi rananta min lagunta, ras pemakenta min pergeluhta, bagepe pendahinta, maka dat buahna situhu-tuhu. Dalam tuturan ini, anak beru menggunakan bahasa kiasan seperti sekula serasi (saling pengertian), rananta min lagunta (seperti yang sudah disampaikan), ras pemakenta min pergeluhta (perbaikilah kehidupan), bagepe perdahinta (begitu juga dengan pekerjaan/karier kalian), dan dat buahna situhu-tuhu (mendapatkan buah/hasil yang sungguhsungguh).

\section{SIMPULAN}

Berdasarkan temuan penelitian di atas dapat disimpulkan tiga hal sebagai berikut. Pertama, tuturan lisan Cakap Lumat dilakukan oleh seseorang atau kelompok sesuai dengan posisinya di dalam tataran adat masyarakat Karo, yakni Kalimbubu, Senina, dan Anak Beru. Kedua, bentuk kebahasaan Cakap Lumat yang dilakukan Kalimbubu, Senina, dan Anak Beru berupa bahasa kiasan, dan perumpamaan. Ketiga, Cakap Lumat berfungsi untuk ucapan salam, konfirmasi, pujian, doa, dan nasehat.

\section{UCAPAN TERIMA KASIH}

Penelitian ini didukung oleh Universitas Nasional, Jakarta. Saya berterima kasih kepada Prof. Dr. Ernawati Sinaga,M.S., Apt, Wakil Rektor Bidang PPMK yang selalu mendukung saya dan memberikan wawasan dan keahlian yang sangat membantu penelitian ini. Saya berterima kasih kepada Dr. Wiyatmi, M.Hum dan Dr. Anwar Efendi, M.Si atas bantuannya terkait dengan teknik, metodologi, dan juga komentar yang sangat baik dalam memperbaiki penelitian ini. Saya juga berterima kasih kepada Prof. Dr. Suminto A. Sayuti untuk motivasinya sehingga saya dapat menyelesaikan naskah penelitian ini.

\section{DAFTAR PUSTAKA}

Anderson J. (2015). Mission to the East Coast of Sumatra in 1823, Singapore: Oxford University Press.

Fitriani. (2018). Membangun Bina Damai Melalui Sistem Kekerabatan (Dalihan Na Tolu dan Rakut Sitelu) di Kabanjahe Kebupaten Tanah 
Karo. Jurnal Studia Sosial Religia, 1(2), 40-49. http://jurnal.uinsu.ac. id / index.php/ssr/article/ view/6479/2821.

Kushnick, G. (2015). Bibliography of Works on the Karo Batak of North Sumatra, Indonesia: Missionary reports, anthropological studies, and other writings from 1826 to the present". http://faculty.washington. edu/kushnick/biblio.htm. (accessed 23/03/19)

Ginting, H. F., Hidayah, N., \& Lasan, B. B. (2019). Profil Meaning of Life Siswa Budaya Karo. Jurnal Pendidikan, 4(2), 242-246. http:// journal.um.ac.id/index.php/jptpp/ article/view/12009/5692.

Ginting, J. F. (2016). Eksistensi Adat Istiadat Karo dalam Pembentukan Masyarakat Multikultural. http:// jasafadilahginting.blogs pot . com/2011/.(accessed 13/10/18).

Ginting, S. U. B. \& Sadikini, M.A. (2018). Analisis Semiotik pada Pesta Perkawinan Adat Karo Langkaat. Jurnal Serunai Bahasa Indonesia, 15(2), 12-21. https://ejournal. stkipbudidaya.ac.id/index.php/je/ article/view/52/45.

Ginting, S. U. B. \& Efendi B. (2017). Bentuk Kesantunan dalam Tindak Tutur Perkawinan Adat Karo. Tangerang: Mahara Publishing.

Ginting, S.U. B. (2017). Semiotik Makna pada Wacana Ngembah Belo Selambar Adat Karo Langkat (Kajian Semiotika Sosial. Jurnal Pena Indonesia (JPI) Jurnal Bahasa Indonesia, Sastra, dan Pengajarannya, 3(2), 130-14. DOI: http://dx.doi. org/10.26740/jpi.v3n2.p130-146.
Girsang, C. K., dkk. (2019). Analisis Proses, Fungsi dan Nilai Didongdoah Bibi si Rembah Ku Lau dalam Upacara Perkawinan Adat Karo. Jurnal Pendidikan Bahasa dan Sastra Indonesia, 4(1), 196-203. https:// jurnal.uisu.ac.id/index.php/ Bahastra/article/view/1722/1307.

Hartati, S. (2015). Jenis, Makna, dan Fungsi Peribahasa Maanyan (Type, Meaning, and Function of The Maanyan Proverb. Jurnal Bahasa, Sastra, dan Pengajarannya. 5(2), 255271. http://prints.ulm.ac.id.

Kipp, R. S. (2017). Disociated Identities: Ethnicity, Religion, and Class an An Indonesian Society. Michigan: University of Michigan Press.

Krause, K. W. 2008. Mapping Metaphor: This Is Your brain on Figurative Language. America.

Kusmayati, A. M. H., dan Sayuti, S. A. (2014). Esksistensi Sasra Lisan Mamaca di Kabupaten Pamekasan Madura. Litera Jurnal Penelitian Bahasa, Sastra, dan Pengajarannya, 13(1), 182-190. DOI: https://doi. org/10.21831/ltr.v13i1.1914

Lubis, M. A. (2017). Budaya dan Solidaritas Sosial dalam Kerukunan Umat Beragama di Tanah Karo. Jurnal Ilmiah Sosiologi Agama dan Perubahan Sosial, 11(2), 239-258. DOI: https:// doi.org/10.14421/jsa.2017.112-06.

Lubis, M. (2018). Pursuing a Passion for Service and Justice" http:// 1 ifeandletters.1a.utexas . edu/2018/08/pursuing-a-passionfor-service-and-justice/, (accessed 17/03/19).

Perrine, L. (1983). Literature: Structure, Sound and Sense. United Stated of 
American: Harcourt Brace Jovanivich.

Pulungan, A. H. (2013). Kajian Etnolinguistik terhadap Peribahasa dalam Bahasa Indonesia: Sebuah Tinjauan Pragmatik Force (Daya Pragmatik). Digitl Repositiry. http:// digilib.unimed.ac.id/419/.

Sembiring, C. D. A. (2016). Penguatan Identitas dalam Media Komunitas. Tesis Universitas Gadjah Mada. http://etd.repository.ugm.ac.id/.

Singarimbun, M. (2015). Kindship, Descent and Alliance among Karo Batak, Berkeley: University of California Press.

Singarimbun M. 2017. Kutagamber: a Village of the Karo, Singapore: Equinox Publishing.
Sulissusiawan, A. (2016). Peran Mahakam dalam Adat Perkawinan sebagai Representasi Adab dan Etika Melayu Sambas. Litera Jurnal Penelitian Bahasa, Sastra, dan Pengajarannya, 15(2), 351-365. DOI: https://doi.org/10.21831/ltr. v15i2.11834

Tarigan, H. G. (2011). Sastra Karo Selayang Pandang. https://Karo. or.id / sastra-Karo-selayangdipandang/ (accessed 12 December 2019)

Wainwright, J. 2004. Poetry: The Basics. London : Routledge. 